\title{
Energy Estimation on BLDC Electric Vehicle Using Matlab
}

\author{
Hasnira $^{1}$ and Didi Istardi ${ }^{1}$
}

\begin{abstract}
The need for an efficient electric drive system which has high torque and speed, low maintenance costs is getting increased. However, the motors which are commonly used, such as induction motors and DC motors, have not been able to meet the need. Therefore, a new model with efficiency System and energy consumption using simulated software "MATLAB ${ }^{\circledR}$ or Simulink ${ }^{\circledR} "$ is made. This model includes battery, power electronics converters, electric motors, and transmission systems. In this case the energy system during regenerative braking breaking is also taken into account. The result of the efficiency value of the batteries, inverter, electric motor and the total efficiency value of the overall system is gathered from the control Brushless Motor (BLDC) models HHDB 350-1000 Watt and some batteries type SOC with capacity 34-48 Ah used.
\end{abstract}

Keywords—BLDC, Matlab, Simulink, electric Motor.

\section{INTRODUCTION}

E lectrical vehicle was a green traction drive that will be a replace of conventional vehicle. The development of electric vehicle was rapidly increase due to enviromental issue and fossil fuel issue. Due to this condition, there are a lot of research on electric traction drive fields.

The components of electric vehicle are chassis made of a steel tube, a propulsion system that includes an electric motor that drives the wheels, a power electronic converter that regulates the energy flow to the motor and a transmission system, a battery that provides energy, and a control unit that ensures a proper operation of the power electronic converter.

In electric traction drive system, the electric motor was a main component that effect the performance of the system. the comparison of electric motor that used in the electric traction drive system was explained [2]. The BLDC motor (Brushless Direct Currrent Motor) have a better performance than IM (Induction Motor) in this system.

According to this phenomena, costs has a big effect the selection of components and equipment used in the electric vehicle. The use of fossil fuels is a large - scale in today's automotive industry has also resulted in the world's energy reserves decreased significantly to near the critical point. In addition, it also brings a number of negative impacts which cannot be underestimated because it is closely related to human survival and environmental sustainability. Therefore, the exact calculation of energy usage, the equipment used and the cost must be accurate.

In this paper is described about modeling systems on electric cars. By using a Brushless DC motor (BLDC) models HHDC 350-1000W, and the battery SOC type with a capacity of 36-48 Ah, and the controller so that efficiency can be known. The sequence of the preparation of this paper as follows: in Section II, the theory of electric vehicle will be explained. There are the electric motor, power electronics conveter, storage energy, and transmission systems that will be presented.

\footnotetext{
${ }^{1}$ Hasnira and Didi Istardi are with Departement of Electrical Engineering, Politeknik Batam, Indonesia. E-mail: nierha84@ymail.com; istardi@polibatam.ac.id.
}

In section III, the system duty cycle of the electric car will be explained. Type of modeling that is made can also be explained. Part IV will explaiined about the simulation results using the software MATLAB ${ }^{\circledR}$ or Simulink ${ }^{\circledR}$. And conclusions will be made in section $\mathrm{V}$.

\section{DRIVE SYSTEM IN ELECTRIC CARS}

Electric Cars at the drive system consists of a drive system (electric motors, power electronics, and transmission) and energy storage (batteries) as by figure 1.

From the diagram above, clearly visible propulsion systems work on electric cars. Here energy is stored in the battery and power electronics converter will connect the battery to the electric motor. Voltage and output current of the battery will be maintained to be consistent with the rating of the electric motor is used. Electric motors convert electrical energy into mechanical energy, and a transmission will convert mechanical energy into linear motion. A controller and processing energy is used to control the speed and direction of the electric car, here also serves to optimize the conversion of energy from the battery to the transmission. The battery can be charged from the grid as well as from regenerative braking energy.

\section{A. Energy storage (batteries)}

Modeling can also use a battery electric circuit based on the electrical characteristics of the battery. In this paper, modeling generic batteries will be used. The model is a modification of the model of battery discharge and introduced by Sheppard. Modeling using source voltage of the battery is connected in series with a constant resistance representing the four types of batteries available in the market such as $\mathrm{NiMH}$ and $\mathrm{Li}$ ion and the output voltage can be calculated with:

$$
\begin{array}{ll}
E=E o- & K\left(\frac{Q}{Q}\right) i+A_{e}{ }^{(-B] i d t)} \\
& \text { Q - } \int \text { idt } \\
\text { E } & : \text { Battery Output voltage [V] } \\
\text { Eo } & : \text { Open Voltage [V] } \\
\mathrm{Q} & : \text { The battery capacity } \\
\mathrm{K} & \text { : Coefficient polarization } \\
\mathrm{I} & \text { : Current density [A] } \\
\mathrm{Q} & \text { : Elapsed time [h] }
\end{array}
$$

In the simulation will be used as an energy storage battery with a capacity of about 36-48 Ah. 


\section{B. Power Electronics Converter Systems}

Power electronics converter that will be used in this simulation is a kind of controller H-Bridge converter for Brushless DC Motor (BLDC). The main function of this component is to provide a signal corresponding to the amount needed by the electric motor. Power electronic components used here are MOSFETs (Metal Oxide Semiconductor Field Effect Transistors), IGBT (Insulated Gate Bipolar Transistor), and a power diode. Pulse controller used in this simulation is a three-phase pulse-width modulation (PWM). Although for the controlling BLDC motors typically use a trapezoidal wave modulation. The major loss in converter (PQ) is the loss due to the switching (switching Pswitch, Q) and for conduction (Pcond, Q) and can be calculated by:

$\mathrm{P}_{\mathrm{Q}}=\mathrm{P}_{\text {condQ }}+\mathrm{P}_{\text {switchQ }}$

where:

$\begin{array}{ll}\mathrm{P}_{\mathrm{Q}} & \text { : major losses converter } \\ \mathrm{P}_{\text {cond,Q }} & \text { : conduction losses } \\ \mathrm{P}_{\text {switch,Q }} & \text { : switching losses }\end{array}$

\section{Electric Motor}

Losses in electric motors can be divided into 4 components: cable loss (core losses), core losses, mechanical losses and losses due to other causes. In this paper, it's only the cable losses and core to be used in the simulation and analysis. Mechanical losses and losses due to other causes are ignored. Electric motors are used in this paper is the BLDC motor.

Brushless DC motor rotor is a permanent magnet to form a bow. Used permanent magnets aims to provide high efficiency. Permanent magnet is placed against the surface of the rotor section. This is done in connection with the attempt to produce a near-linear characteristic. The electronic circuits can be designed to produce a current in the form of a square wave and sine wave. Square-wave-shaped flow is best choice for Brushless DC motors because these waves are not a source of harmonic losses such as AC motors. Losses in the motor can be calculated by:

$P_{\text {loss }}=2 R_{s} I_{S}^{2}$

Where :

$\mathrm{P}_{\text {Loss }} \quad$ : Power Losses

$\mathrm{R}_{\mathrm{s}} \quad$ : Resistance (Ohm)

$\mathrm{I}_{\mathrm{S}} \quad$ : Curent (A)

\section{Transmission modeling}

Losses in electric motors can be divided into 4 Transmission system is a system whose function is to convert the torque and speed (rotation) of the engine torque and speed to be different to be forwarded to the final drive. This conversion changed the high rotational speed is lower but more powerful, or vice versa. The output of the transmission system is speed, which is obtained the equation:

$\omega=\frac{T_{\text {acc }}}{\text { inertia }}$

where:

$\omega=$ Speed $(\operatorname{rad} / \mathrm{s})$

$\mathrm{T}_{\text {acc }}=$ torque acceleration

Inertia = moment of inertia [kg.m ${ }^{2}$ ]
The speed of motor is influenced by the motor torque and moment of inertia-value. Modeling of the transmission system can be shown by figure 2 .

\section{E. Regenerative braking}

This mechanism occurs when the condition reduces vehicle speed by converting kinetic energy to most other types of energy. This energy can also be used to charge the battery. On modeling regenerative braking will be compared to the value of the current in the stator to the conditions at the time of the motor performance. If the value of issued more than 1 then the condition of the motor is normal, but if the excluded value is less than 1 , this is called the braking conditions. Equation - The following equation is used for modeling during regenerative conditions.

$P_{\text {loss }}=P_{\text {cu }}+P_{\text {core }}$

$P_{c u}=2 * R_{s} * I_{a}^{2}$

$P_{\text {core }}=k_{h} \omega .+k_{e} \omega^{2}$

$P_{\text {motin }}=\left(P_{\text {motout }}+P_{c u}\right)-P_{\text {loss }}$

Calculation of efficiency values can be searched by:

eff $[\%]=\frac{\text { Pmotout }}{\text { Pmotin }}$

Description:

$\mathrm{P}_{\text {loss }} \quad=$ Power Losses

$\mathrm{P}_{\mathrm{CU}} \quad=$ Power Losses in copper

$\mathrm{P}_{\text {cor }} \quad=$ Losses in the core power

$\mathrm{R}_{\mathrm{s}} \quad=$ Stator resistance [ohm]

$\mathrm{I}_{\mathrm{a}} \quad=$ Stator current $[\mathrm{A}]$

$\mathrm{k}_{\mathrm{h}} \quad=$ coefficient value hysteresis losses

$\mathrm{k}_{\mathrm{e}} \quad=$ Value coefficient on condition of eddy current losses
$\mathrm{P}_{\text {motin }} \quad=$ motor power input
$\mathrm{P}_{\text {motout }}=$ motor power output
Eff = Efficiency motors

Regenerative braking is different from the dynamic braking electrical energy dissipates as heat by passing curre nt through a variable resistor and has a small effect on low speed. Therefore, the friction brake is still needed as a backup brake. Total energy converted to be limited by the capacity of energy absorption or by (SOC) battery. If this condition is met, the dynamic braking will absorb the excess energy. In regenerative braking, the electric motor functions as a generator during braking and kana energy supplied to the load which provides the braking effect. This regenerative braking will run if the value of the total torque is negative value.

\section{F. Modeling of the Electric Car Drive System}

Modeling of the system use Matlab/Simulink software. According form Figure 1, the system can be modeled as Figure 3.

It consists of six main blocks: The charger, Battery, Conversion, electric motor, transmission and energy. Each section has an important role to drive the system and is closely connected with each other. This modeling is very suitable to analyze the efficiency and performance of the system. Figure 3 shows that the reference system is the load torque input representing the load profile of the cycle. 


\section{RESULT AND DISCUSSION}

From the results of energy modeling system estimates made electric car, the result output efficiency values as follows. In input of the system uses the track system on Batam Polytechnics Campus area and it runs for a lap.

\section{A. Battery output BLDC}

Energy use in the drive system can be calculated by integrating the use of power in the drive system of the time. At this time the battery used is the SOC (state of charge). By using the battery voltage $36 / 48 \mathrm{~V}$ then the battery efficiency of the output signal can be seen in Figure 4 below.

Battery performance in the drive system can be evaluated using the SOC of the battery. SOC of the battery can be seen in Figure 5. Down the line shown in the Figure indicate no charging of batteries on regenerative braking. Regenerative braking energy can be used to charge the battery and reduce the use of energy in the system. SOC of battery is 0.999 .

\section{B. Converter Effisiensi}

Figure 6 below is a result of efficiency that occurs in modeling converter. With 2287 times the data retrieval time, the efficiency values obtained on condition steady state is $93.7 \%$.

\section{Conditions Energy In Electric Motors}

Energy conditions in the BLDC motor can be seen in the following image signal output, wherein energy BLDC motor is $350 \mathrm{~W}$ and the total efficiency is the sum of the maximum efficient value generated by the battery, converter and motor.

$$
\begin{aligned}
\text { Eff_total [\%] } & =\text { Eff_bat } * \text { Eff_conv*Eff_mtr } \\
& =0.979 * 0.937 * 0.896 \\
& =82.2 \%
\end{aligned}
$$

In Figure 7 can be seen the output value of total efficiency.

The total yield was $82.2 \%$ efficiency, the parameter values obtained from the efficiency of the battery at 97.9\%, 93.7\% converter, and a 350W BLDC motor of $89.6 \%$.

\section{Torque}

Value of the torque produced by the BLDC motor is 44 $\mathrm{Nm}$. As for the battery on the system performance drive systems in electric cars can be evaluated using the SOC of the battery. Figure 8 below is a signal output torque of the BLDC motor modeling results.

\section{CONCLUSION}

From the simulation results of energy in electric cars can be concluded:

1. Battery efficiency used is: $97.9 \%$

2. BLDC Motor Efficiency: $89.6 \%$

3. Efficiency in inverter: $93.7 \%$

4. The total value of the efficiency is: $82.2 \%$ Modeling electric drive systems in cars by using the software MATLAB ${ }^{\circledR} /$ Simulink ${ }^{\circledR}$. This modeling includes modeling of electric motor (BLDC), converters, power electronics, and batteries both for normal conditions and during braking.

\section{REFERENCES}

[1]. Cardoso, C., Ferriera, J., Alves, V., Araujo, R.E. 2006. The design and implementation of an electric go-kart for education in motor control. Proceeding of IEEE International Symposium on Power Electronics, Electrical Drives, Automation, and Motion, pp. 1489 - 1494.

[2]. Didi istardi, Comparison of Electric Karting Modeling Using Matlab ${ }^{\circledR} /$ simulink ${ }^{\circledR}$ Software, Malaysia, January 2011

[3]. Didi Istardi, Modeling and Component Selection for a Micro Electric Carting Using different Electric Motor and Battery Types, Batam, March 2010

[4]. Baldurson, S., 2005. BLDC Motor Modeling and Control-A Matlab ${ }^{\circledR} /$ Simulink ${ }^{\circledR}$ implementation. Master Thesis Electric Power Engineering Chalmers.

[5]. Smeaton W., Robert, Switchgear and Control Handbook, pages 29-2

[6]. James Larminie and Jhon Lowry , Electric Vehicle Technology Explained

[7]. Jose Fernandez Ramos and Foroohar Aghili Khatir, Electrical Vehicle Base On Standard Industrial Component, Granada (Spain), March 2010

[8]. S. De Breucker, K. Clement, K. Elngelen, P. Tant, J. Verveckken, P. Jacqmaer, J. Driesen and G. Deconinck, A Hybrid Electric Kart with Energy Flow Management as a Student Project, 2008.

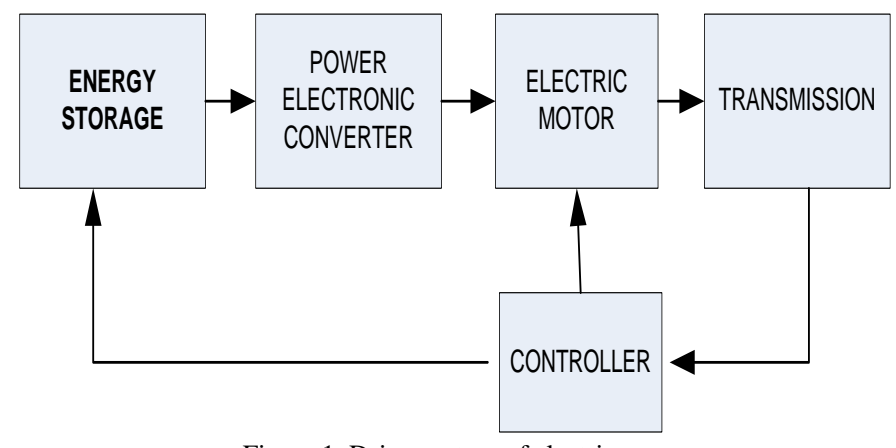

Figure 1. Drive system of electric cars 


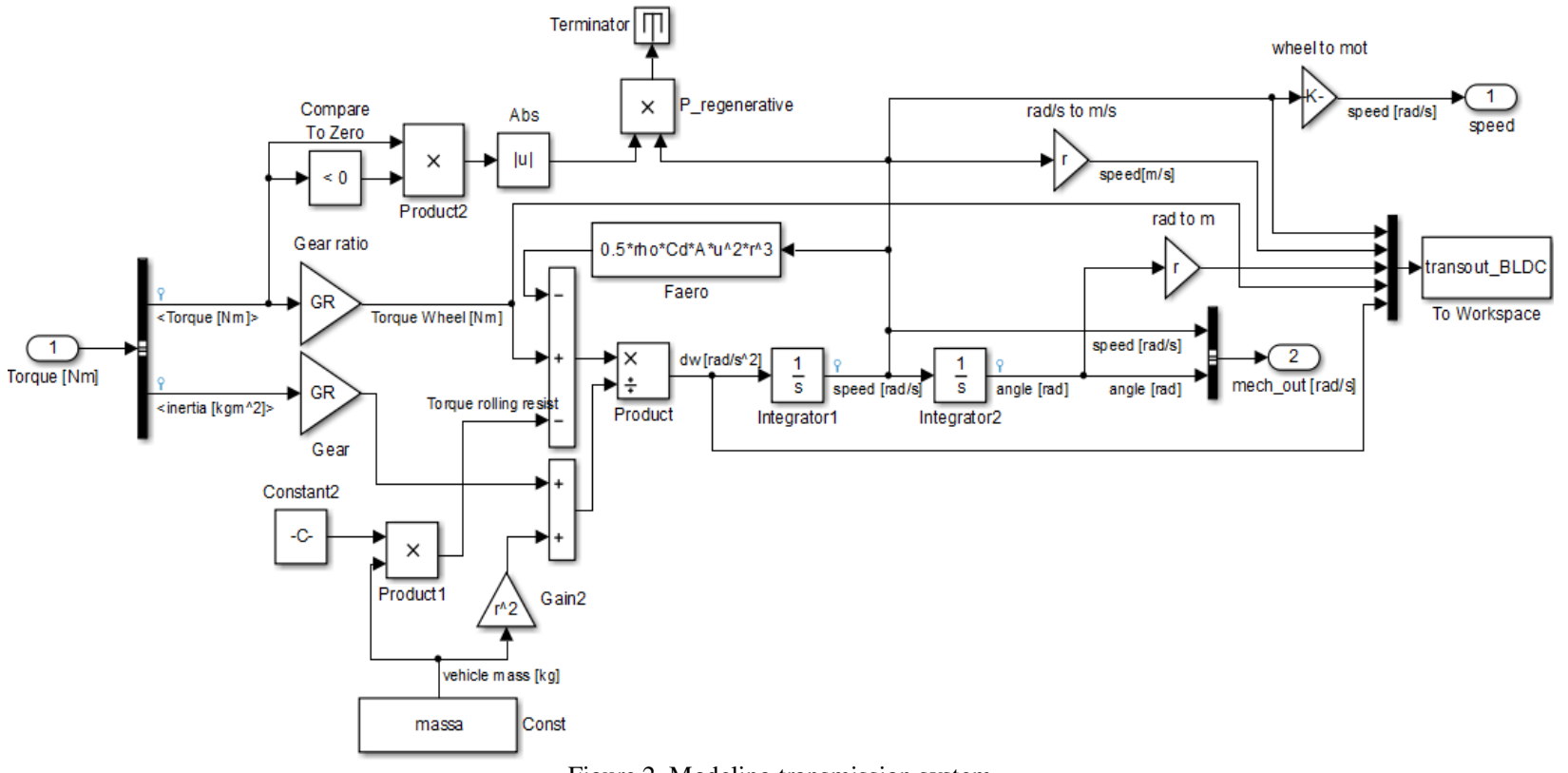

Figure 2. Modeling transmission system

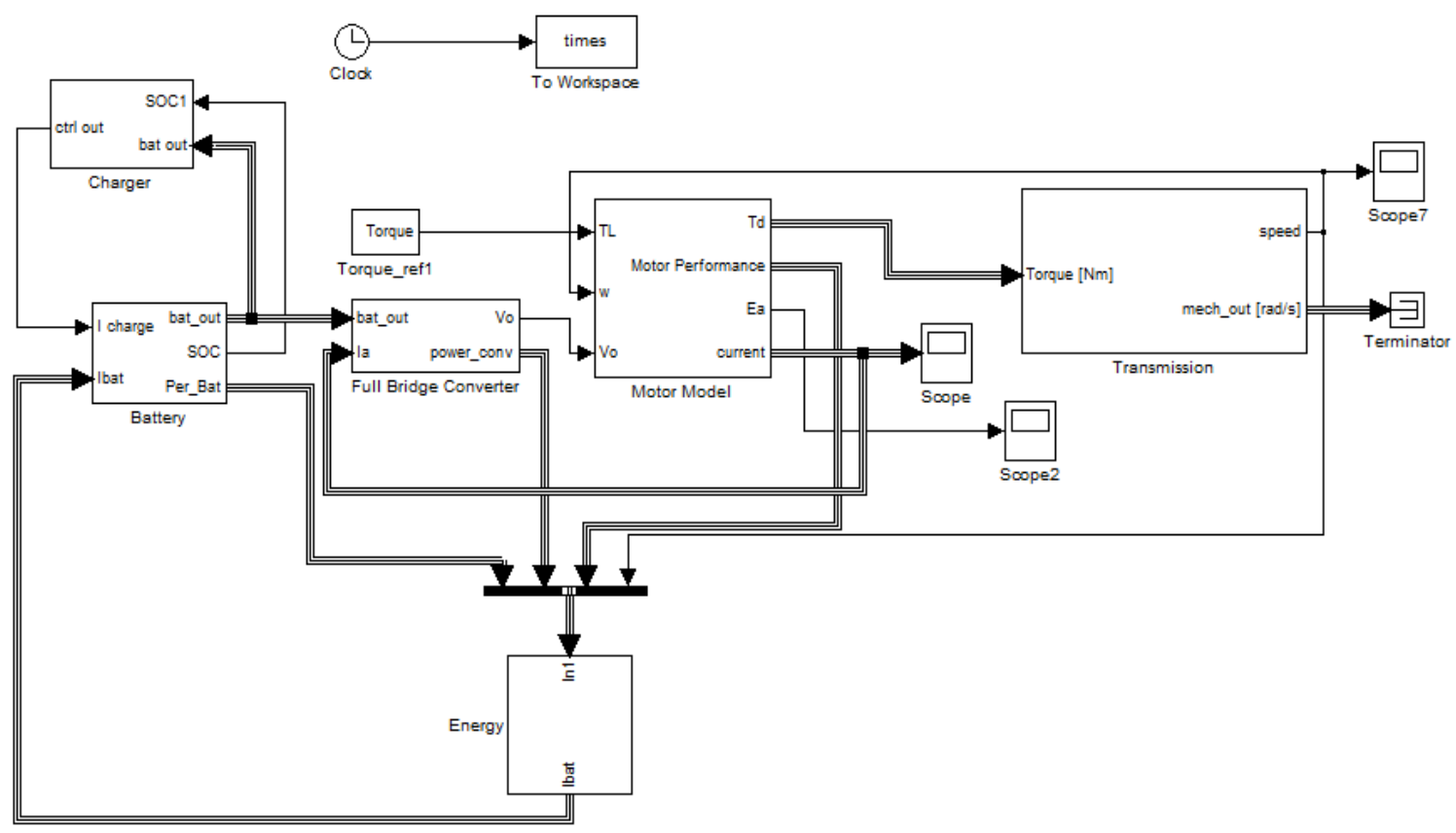

Figure 3. Modeling system on the driving electric cars by using Simulink



Figure 4. Battery efficiency

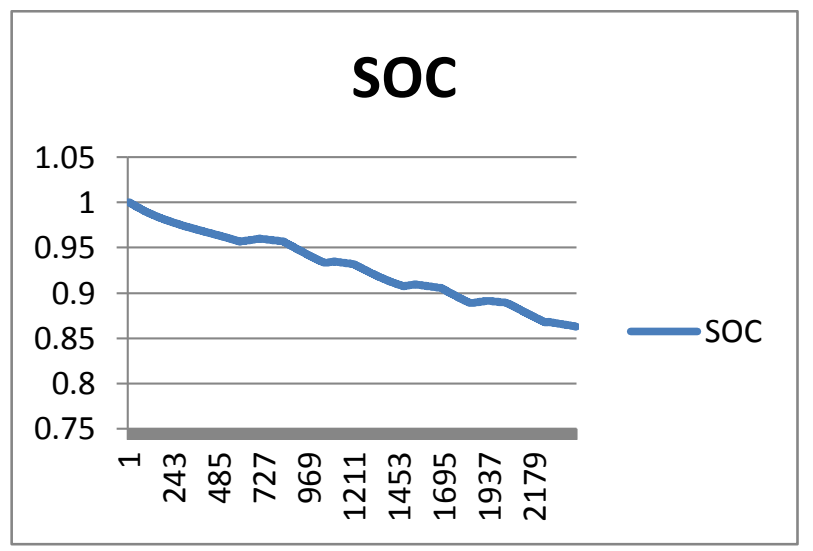

Figure 5. Output signal of SOC 


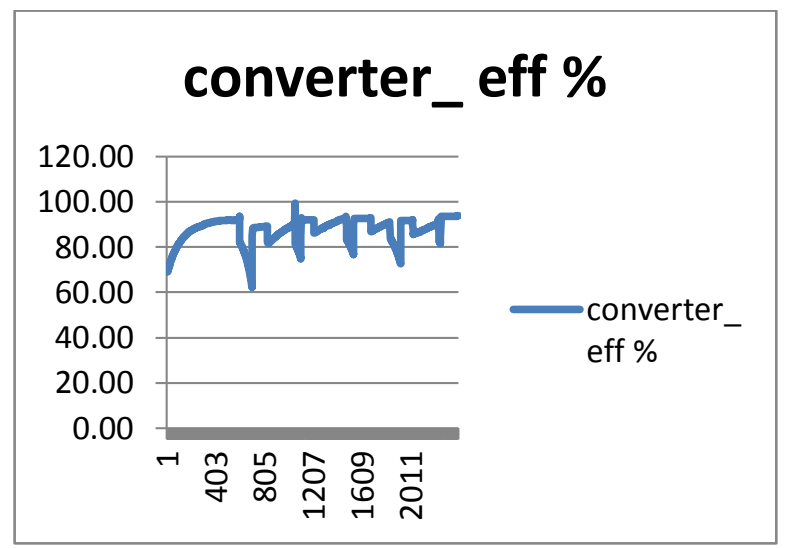

Figure 6. Conversion efficiency

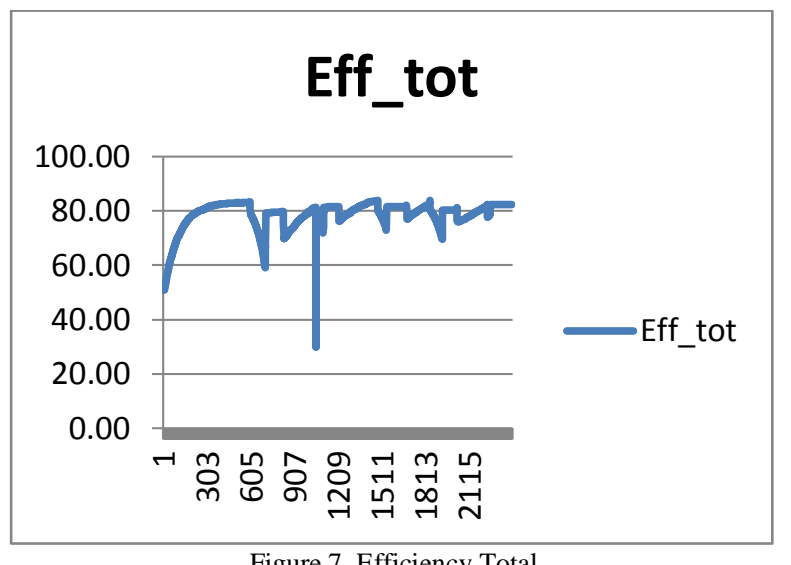

Figure 7. Efficiency Total

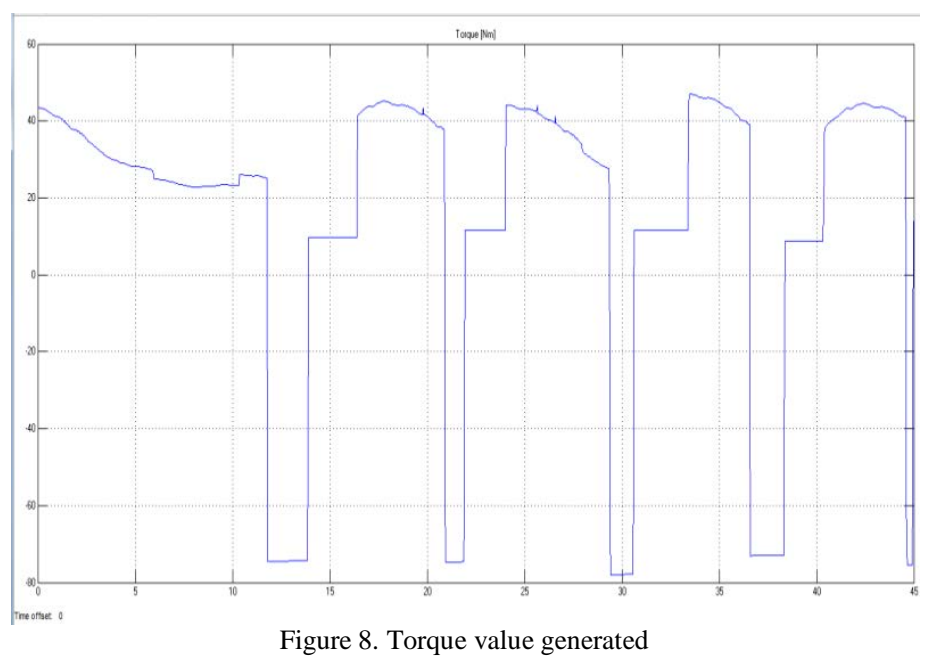

